\title{
Propositions toward the development of a psychological theory of thought
}

\author{
Vladimir D. Shadrikov ${ }^{\mathrm{a}}$, Sergey S. Kurginyan ${ }^{\mathrm{b}^{*}}$ \\ ${ }^{a}$ Faculty of Social Sciences, National Research University Higher School of Economics, \\ Moscow, Russia \\ ${ }^{b}$ Faculty of Social Sciences, National Research University Higher School of Economics, \\ Moscow, Russia \\ ${ }^{*}$ Corresponding author. E-mail: skurginyan@hse.ru
}

\begin{abstract}
Thought is considered a psychological concept associated with an individual's mental existence. It is apparent that a great deal of research has been focused on thought as an area of study. However, there is no psychological theory of thought which provides an explanation for its nature and structural organization. So far, researchers have mainly looked at the ways this concept is expressed, rather than investigating what it actually is. In this study, however, based on studies of the functions of the psyche, mental processes, and the neurophysiological bases of mental activity, thought is identified as a need-emotionintentional substance existing in the human being's inner world. In keeping with this understanding of thought, the hypothesis that thought generation is caused by desire and experience (feeling and emotion) is put forward. An individual's thought is linked to his behavior or motivation for activity, and is followed by an emotional experience. The process of thought generation is regarded through the mechanism of behavioral motivation. The primary purpose of this mechanism is to define the qualities of the external objects that serve for need satisfaction and functionality in individuals. The ability to generate thoughts is a feature of thinking related to an individual's mental ability or frame of mind. From this standpoint, a person's mentality is considered to be the capacity of the individual to generate thoughts and work through thoughts. It is shown that the ability to generate thoughts and establish relationships within a stream of consciousness is characteristic of human intelligence. Some basic propositions toward a development of a psychological theory of thought are introduced.
\end{abstract}

Keywords: mental processes, function of the psyche, substantial thought, thinking ontology, thought

\section{Introduction}

Words such as thought, thinking, and awareness are commonplace in every-day language. Thus it would appear that anyone, at a prescientific level of understanding, could easily explain these terms. However, we encounter difficulties if we try to 
define them scientifically. The best minds of mankind have been addressing those concepts for two millennia, in an attempt to expose the nature of the human mind. In dealing with the nature of thought, they have attempted to define the relationship between an individual's thought and the words he pronounces.

Aristotle (ca. $350 \mathrm{BCE} / 1930$ ) regarded the thought and the word as a unity, and identified them neither with each other nor with the thought's object. In his considerations he stated that the apperception of a thing is the source of the thought. John Locke (1979) proposed that thought may appear without language. In contrast to Locke's view, Leibniz believed that language is intended for an individual's discourse with himself (as cited in Ishiguro, 1990). Wilhelm von Humboldt had a similar opinion. He considered thought impossible without language (von Humboldt, 1984). While Potebnja (1926) pointed out the limited unity of thought and the word, and referred to the distinction between them, he asserted that rudimentary thoughts could exist without words.

The arguments for the relationship between thought and word produce other opinions as well. Nevertheless, issues such as "What are the thought content and its structure?", "How does it function and what are the mechanisms of its generation?", and "How does thought relate to image, idea, and notion?" have not been examined in the context of original research. This is an important omission which identifies the gap between the science and theory of thought.

In psychology, as in other scientific studies, there are issues which have great significance in daily life which are not subjected to theoretical examination. One such issue is the understanding of human thought. A particular problem yet to be adequately addressed is how any theory of thought can provide the basis for introducing thought as a concept into the conceptual framework of any scientific study. Currently, thought is a subject of great importance in the study of the psychology of thinking. A certain contribution has been made by cognitive science, drawing on aspects of the philosophy of mind, epistemology, cognitive psychology, linguistics, neuroscience, anthropology, and computer modelling. The development of this interdisciplinary approach to understanding the mind and mental processes has resulted in identifying thought with information.

By making the psychological shift from the mind to the mental processes, many scholarly works have avoided the problem of the relationship between an individual's thoughts and cognition associated with representation, imagination, and conceptualization. Research in cognitive psychology, where the human brain and mind are regarded as a computer, provide some obvious examples. When cognitive psychologists present empirical models of imagination, perception, thinking, and other mental processes, they usually pay little attention to the products of these processes (image, sense, thought, etc.). Any cognitive model will be de facto inefficient if its interpretation is based on undefined psychological concepts. It also seems impossible to understand these psychological realities (or mental processes) without reference to the individual's thoughts as they are carried out in particular processes.

In this regard we face the fact emphasized by Zinchenko that thought has gradually lost ground in practice of psychology, and thinking has been seen in isolation from thought (Vasiljuk et al., 2012). Some recent studies of thought have viewed the concept within the larger context of its functions. Thus, some researchers conceptualize and study thought as an idea or opinion produced by a thinking subject, 
or occurring suddenly in his mind; others regard it as an action or a process of thinking. Considering thought as a psychological concept, they nevertheless neglect its substantive interpretation as a mental entity.

Currently, there are a great number of studies that deal with thought through investigation of applied problems (Bos et al., 2012; Hart et al., 2013; Simonton, 2013; Smallwood, 2013; Thomas, 2013; Altmann et al., 2014; Becker et al., 2014; Bright \& Feeney, 2014; Gallagher et al., 2014; Huntsinger et al., 2014; Logan et al., 2014; Avugos \& Bar-Eli, 2015; Lohnberg \& Altmaier, 2014). As such, we are witnessing the emergence of many singular reflections on thought content in different areas of psychology, especially in philosophical psychology, general psychology, cognitive psychology, the psychology of individual differences, clinical psychology, counseling psychology, and psycholinguistics.

But in these areas of psychological study, the fact remains that researchers focus their attention on what the thought is expressed in, rather than deal with "what the thought actually is." In theory we have not gotten over the difficulty of considering the content of the category of thought. So far researchers have not presented any definite structure of the thought. This is a complex task. To understand the content of thought, any psychological study should first address the ontology of thought. Thus, we will approach this issue by shifting from an ontology of thinking to an ontology of thought.

\section{Ontology of thinking}

The ontology of thinking was widely covered in S.L. Rubinstein's work. (Rubinstein, 1958). He stated that the only function of thinking was to become aware of being. In his understanding, being is the material world that has become an object in the evolutionary process of individuals. Owing to their interrelation with the world, individuals manifest themselves as subjects of action and cognition. According to Rubinstein's definition, to be a subject is to be able to change and explore the world. The psyche has played a pivotal role in that continuous interrelation of the individual with the world. By changing the world, the individual changes himself. By reflecting this persistent changeability, the human psyche acquires distinctive properties such as dynamism and flexibility. Therefore the psyche reveals itself in the process. This is a principal feature of psychological processes.

The central thesis of Rubinstein's theory concerns how the human being and his/her psyche perform and develop in an activity. Here the activity is understood as the way the subject relates to reality. In keeping with this understanding, the psyche manifests itself in the activity as a mental process, and in the product of this process. Rubinstein holds that the key task of any psychological research is to study mental processes and mind activity. As such, the study of thinking has to primarily involve examining it as the process of analysis, synthesis, and generalization. These processes are carried out by the individual's mind, and thinking is his activity relating to the mind. Thus thinking is regarded as a mental activity which manifests itself to the individual through his motives. This is one aspect of thinking as an activity that is relevant to analyzing the personality of the individual. Another aspect is the procedural side of thinking, which consists of analysis, synthesis, and generalization. Thus, Rubinstein understands thinking as a process consisting of 
a set of mental operations, and as an activity. In this regard he asserts that the individual thinks, rather than that something is merely thought by the individual (Abulkhanova-Slavskaja \& Brushlinskjy, 1989).

The experimental studies Rubinstein conducted led him to the conclusion that the opportunity for the individual to acquire and apply knowledge offered from outside (such as conceptual generalization and ways of acting) depended on the extent of the development of individual's internal conditions for knowledge acquisition and application. Here the external causes act only as a result of internal conditions. As such, the auxiliary tasks (strictly measured prompts) presented in the experiment are objective indicators of the inner train of thought and its progression in problem solving. Rubinstein's approach to the experimental study of thinking is based on the deterministic principle that external causes act through internal conditions. The external action has an effect on the psyche by being refracted through an individual's mental states and his existing thoughts and feelings. His experimental technique is based on understanding the role played by the relationship between social and individual experience in one's psychological development. An individual's social experience depends on the extent of interaction between the external causes and his internal activity. In this respect one aspect that may be beneficial to focus on is the person's thinking about his/her social reality in its phenomenological and essential features (social processes, events, situations, human relationships and behavior, and personalities), as well as about his/her own life.

With regard to social cognition, Abulkhanova (1999) suggested that understanding the nature of a person's social thinking depends upon the position they have in society and life. This kind of thinking is carried out in the person's actions, and expresses the generalization of his/her adopted way of life. Research has demonstrated that a person's specific life-style directly depends on their social thinking (Abulkhanova-Slavskaja, 1994). As to be expected, these findings lead researchers to think about the inverse dependence of the regulatory function of social thinking on the individual's life-style.

Abulkhanova and colleagues have stated that nowadays it is necessary to find out about the potential for a person's thinking to adapt to new social environments, and to define the contribution of the person's intellectual powers to personality efficiency. As such, thinking is considered as a person's vital ability. In Abulkhanova's model of personality, social thinking is understood as a psychosocial construct which is a mental, personality product, rather than an immanent characteristic of the personality. Being an active subject in its own life, a personality has the vital ability of this kind of thinking and has need for it. Personality awareness, which refers to what is acquired through experience in different periods of life, is manifest in the perception and comprehension of an event, a situation, another person, one's own behavior, and life as well. This is an actual awareness provided by the thinking personalityin other words, by the person's analysis, comparison of vital events, search for their causes and consequences, and understanding of their meaning. Here meaning refers to one's individual consciousness, mind, and intelligence, which enable one to think about the fundamental essence of experience and reality.

From Rubinstein's perspective, to study mental processes is to study the formation of their results and products (mental imagery, thoughts, stable feelings, etc.). Irrespective of any formation of the psyche developed in a mental process, 
it would be difficult to distinguish one specific process from others. This is most likely true because the formation of the psyche could not exist outside a definite mental process. The mental imagery of a thing is in fact the process which results in its outcome. Based on Rubinstein's perspectives on the ontology of thinking, Slavskaja (1968) in her study introduces thought to the psychology of thinking in order to define the mechanism of the mental activity of human being. She explores the nature of thinking by discussing the difficulties that researchers face in studying thought. Her main discussion centers on the issues of how thought can be investigated, measured, and shaped to one's will. There is still one major issue to be addressed: what is the nature of thought?

\section{The ontology of thought: What is human thought?}

To answer the question "What is human thought?" is to appeal to the issue of the function of the psyche. In general, it could be said that the psyche regulates the relationships of a human being with the outside world, in order to organize the behavior that maintains the individual's existence and life. First, an individual has to be seen as existing. Without existence all the problems of human life disappear. Existing means living in the world. Human life might be defined as the existence of an individual in the outside world from birth to death through his active interaction with the world, the reason for which lies within himself (Shadrikov, 2013). The fact of being based on the need for existence is the most important methodological principle for understanding the human psyche.

But what does a human being need to provide for his existence in the outside world? In the first place, it is necessary to conceive of the world and perceive oneself in functional qualities that define relations with the world on the basis of one's subjective properties. Here the function of the psyche is represented in its providing the human being with information about his environment and organizing his adaptive behavior. It is carried out by such mental processes as perception and sensations.

Cognition of external objects is the way one defines the singleness and uniqueness of a thing, its functional meaning, and identifies ways of detecting its qualities and relationships with other things. The cognition of any thing is closely related to understanding it. Being aware of a thing within the outside world is to acquire knowledge of it through experience and the senses, whereas being aware of some one thing as different from the things in the surrounding world is to understand its singleness, its otherness. Here the acquisition of knowledge about the relationship between things might be considered as understanding the fact that things codetermine each other, while the acquisition of knowledge about qualities of things is considered as understanding their meaning, sense, and functional value. This applies to the comprehension of what the thing is.

Yet there is also another level of cognition that is the explanation of first, why this thing differs from other things; second, what specific certain properties it possesses; third, in what way it relates to other things; and finally, how it shows its qualities and relationships. Thus, it should be said that the cognition of external objects is a process that is carried out in a very deterministic way, using all the mental resources available to an individual for perceiving the external world. 
The cognition of the outside world presupposes picking out particular objects from the environment, marking out their attributes, and defining the meaning of these attributes for the vital activity of an individual. These operations are realized through such mental processes as perception and sensations. As a result, an operational image of the thing and its attributes are created. Thus, the formation of an external object's image, followed by singling out its attributes, is an important function of one's psyche. Here the unity of an image and its attributes should be underlined as a key point, whereas the image without its attributes becomes a phantom. As such, the unity of the image and its attributes is reduced to a thought. The thought is the connection of image and its attributes. This connection might be regarded as the first phase of objective thought formation, while the emerging system of relationships between images and their attributes is regarded as the essential part of a cognitive process. Just as the relationship between the image and its attributes is reduced to the thought, so the nature of the cognitive process is determined by the thought generation and the relationships between the generated thoughts.

By having defined the thought through the relationship between the thing (object) and its attributes, we show only one aspect of the process of thought generation. However, it should be noted that perception is functional in its nature, since the attributes of the perceived thing are always functional. A thing's attributes are directly linked to an activity or action that an individual performs upon the object of perception. Therefore, the thing's attributes are endowed with a certain meaning caused by the specifics of the performed activity. As such, the thought could be viewed as full of special content expressed through the meaning of an attribute associated with the activity of the subject, rather than being the reflection of the relationship between the thing and its attributes. In other words, the relationship between the image of the perceived thing, and the thing's attributes, is realized through a thought which has special functional content. In keeping with the Rubinstein's principle of psychophysical unity in studying the phenomena of objective reality (Rubinstein, 1973), thought could be understood as something that reflects the relationship between the neuropsychological substrate and psychological function. Moreover, the relationship between the thought and the perceived thing is reflected in the thought content. In this regard the content of the thing's image could be regarded as functional in nature.

As has been shown, the content of the external world (as an object or thing) is reflected in the human thought. In each thought only one side of a thing is perceived. As for the image of the thing, it is associated with the thoughts of its (the thing's) outer side. These thoughts' content is henceforth disclosed. The subject aspires to identify their (thoughts') meaning and make personal sense of them. This disclosure is the essence of the thoughts' intellectualization, which happens within the subject's vital activity. An image of a thing and its thought-attributes are merged into a person's life activities, and thus they get their semantics. Hence the thoughtattribute acquires a certain meaning (content), and as a result, the thought is enriched. The same thought-attribute, if included in different situations and different forms of vital activity, will be endowed with new content. All that we stated above characterizes the substantial nature of thoughts. 
The process of thought intellectualization caused by the needs of the thinking subject should be considered separately. Here we would emphasize the issue of the emergence of the motivational state that defines the subject's active relation to external objects. Sudakov (1993) discovered that an actual need related to the life's necessities creates a motivational state. In his study he observed that the chemical selectivity of cortical mechanisms, and the selection of external objects which are capable of meeting the relevant need, arise on the basis of dominant motivation. In keeping with this finding, it should be said that a motivational state related to actual need is followed by emotions. An objectified need in the form of the reflected qualities of external objects involves emotions. Hence, thought that represents the relationship between the satisfaction of an actual need, and the qualities of perceived external objects, is followed by experience.

As a result, we face the problem of the usage of the terms "emotion" and "relation" with regard to understanding the relationship between thought and motivation. The point is that, at the level of neuropsychological mechanisms of behavior organization, we refer to the neural substrate regulating goal-oriented behavior, so we use the language of biological terms; whereas at the psychological level of the problem analysis, we refer to desire and wish, thought and image, and experience as well. The neural substrate of emotions in this case acts as a system of biological detectors that transform the impulses to fulfill needs into the feeling of pleasure or displeasure, under the influence of which the biological need is experienced as a psychological fact. This feeling might be conscious or unconscious. There is a threshold of feeling awareness. Consequently, considering the functional nature of the psyche, thought as the representation of certain qualities perceived in the external object (thing) which are capable of satisfying the actual need, is followed by experience.

Based on the above considerations, we can mark out the components of the structure of thought. They are the content (meaning), the need, and the emotion. The unification of these structural components of thought is living knowledge. The proposed thought structure represents the unique properties manifest in the fact that an individual thinks with thoughts. As such, a thought is structurally based on meaning, need, and emotion, and regarded as a need-emotion-intentional substance. In psychological studies researchers rarely deal with the term "substance." However, as has been pointed out by Rubinstein (1997), we appeal to this term when we need to reflect on the nature of the perceived object (thing, phenomenon, or occurrence). Regarded as a substance, the thought enters the human's inner world and is stored in memory, being associated with the external objects and their attributes, as well as human needs and emotions.

\section{Thought generation: Sources and mechanisms}

Having considered the ontology of thought, we now turn to the issue of thought generation. To deal with this issue is to proceed from the methodological principle that man's being is maintained by his psyche. Traditionally this issue is discussed in cognitive science. In their study of the nature of human knowledge (its content and forms, and the ways in which knowledge is used, processed, and acquired), researchers proceed from the concept of information when they refer to such 
functions of the psyche as memory, visual perception and cognition, thinking and reasoning, social cognition, decision making, and cognitive development. The studies usually distinguish the role of information in organizing human behavior and activities. In psychological studies the concept of information narrows the content of thought to being characterized by meaning. Based on our understanding of the thought as the need-emotion-intentional substance, we put forward the hypothesis that thought generation is caused by desire and experience (feeling and emotion).

The thought of a thing (an external object) that satisfies an actual need is generated by desire. It is desire that directs the subject's search for an object, and thus shapes a thought. This is done through the process of the objectivation of the desire. Thus, the thought refers to the motivation and the content associated with the object that meets the relevant need. Desire is related to the object as well as to the action. Consequently, the thought of the necessary action occurs. It can be said that the shaping of a thought-i.e., the process of transition from desire to thoughtinvolves three stages. In the first stage, a motive (or need) is perceived-a feeling of wanting to have something. This kind of emotional state could be conscious or unconscious. In the second stage, the given feeling under certain conditions is transformed into an objectified desire, and then expressed in the thought of desired object. Finally, in the third stage, the thought of the desired object is implemented through the thought of the action that must be taken in order to use the object for satisfying actual needs. Within this process of thought generation, thinking is determined by its function. Thinking operates within the content of the psyche, which includes images and thoughts of the objects that meet the relevant need, as well as images and thoughts of necessary actions. In this instance the function of thinking is to make a choice of the object, and decide how it can meet the relevant need, thus discharging the motivational state.

This scheme of thought generation may be illustrated with a simple example. Being aware of getting hungry causes the thought of it being time to eat something. In turn, this thought is associated with another: how to do it. If one has a sandwich, one will eat it; if not, the thought of going to some place where one can have a meal will cross his mind. The perception of food in the eating place leads one to the thought of what he/she would like to eat. The purchase of the desired food is followed by the thought of its cost and the thought of one's capacity to pay. As a result of reflecting on the given situation, one comes to the thought of what one could buy and the thought of how he has to do it. Finally, this process is completed by the satisfaction of one's hunger. The process may continue if one does not satisfy his/ her hunger, or if one is assailed by doubts about the purchased food, etc.

In this example we see that the thought is generated by desire. Here thinking is continued by an assessment of the factors that create the satisfaction of desire. Any thought includes a motive (or need) that led to its generation. At the same time the thought generation is followed by experiences (feelings and emotions) related to that motive. This process of thought generation is superimposed on the process of biological motivation. It gets its ontological meaning in understanding the nature of thought.

The process of thought generation is regarded through the mechanism of behavioral motivation. The primary purpose of this mechanism is to define the qual- 
ities of the external objects that serve to satisfy the needs, and aid the functioning of an individual. These qualities primarily refer to the object and are associated with subject's motivation. As has been shown, the relationship between the object and its qualities is expressed in the thought, which is based on a motivation that leads to its (the thought's) generation. This is a way of experiencing the outside world. The latter is transformed into a semantic model within the inner world of the individual.

Thought generation on a psychological level involves an individual's past experience, and his particular knowledge and understanding of an object. Any stage of thought generation is described by the decision-making process based on thinking. In thinking, the psychic content associated with need satisfaction leads to certain solutions reflected in the thoughts. A variety of thoughts related to satisfying needs is integrated into the mental semantic model associated with a particular life activity. This model is characterized by transition from an actual state to a potential state. In similar circumstances it goes back into the actual state. This is how patterns of behavior are developed. Hence, to understand the process of thought generation, thoughts need to be regarded as the need-emotion-intentional substances.

Experience is another source of thought generation. In this case the relationship between the experience and the thought should be brought into the discussion. In this relationship the emotions or feelings that generate the thought are of special interest. There are types of emotions that are super-intellectual in nature (Bergson, 1935). Their function is to follow the creation of new ideas which contain emotional components. Here emotion is involved in the mental state of someone who creates something, and is a cause of this state rather than a consequence.

The conscience might be seen as a locus of strong and stable feelings. As an intellectual phenomenon, the conscience is a moral sense viewed as a guide to one's behavior. It is referred to as one's moral consciousness. As such, it is regarded as a mental state associated with a deep feeling. This state contains subtle thoughts, the concealed content of the psyche. Any act is represented by the unity of developed, unobjectified thought and emotion. The role of conscience in one's behavior is to make one think about and judge one's own actions. The reference to a conscientious deed is another aspect of understanding the thought generation process.

Perception and sensation are mental processes that are originally concerned with thought generation. It is known that any mental process is carried out through mechanisms of physiological functional systems which perform certain mental functions. Contemporary studies in neuropsychology have shown the role of the brain's processes in manifesting these functions. However, it should be pointed out that a key problem discussed by researchers in their neuropsychological studies when they investigating processes such as cognition, thinking, and perception, is to define the neuropsychological mechanisms of mental representation or imaging and the attributes which make up an image.

A classic example of the studies in this field is the work of Pribram. He asserted that perceptual processes have to be studied through detailed analysis of attributes (Pribram, 1971). As such, attributes are related to the image, and this relationship characterizes substantial thought. The emerging system of the relationship between 
an image and its attributes is essentially a cognitive process. This process is characterized by thoughts relations, since the thought carries out the relationship between the attribute and the image.

The neuroscience research supervised by Bekhtereva created the neuropsychological background for understanding the generation and functioning of human thought. She showed the close relationship between emotional and mental activity (Bekhtereva, 1978). The experimental findings from these studies are being used to prove our assertion of the unity of mental, motivational, and emotional thought components. The investigation of the neurophysiological bases of mental activity related to the perception of semantic features and elementary mental operations, has shown that the reflection of semantic features is associated with reorganization of the impulse activity of neural populations, and that there exist neurophysiological signs of semantic generality. The neurophysiological correlates of elementary mental operations were indicated in her studies. In her work Bekhtereva comes to the interesting conclusion that the deciphering of the brain code assigned to the representation of the mental processes is a matter of time and technological development. Yet she acknowledges that there also exists something ideal which needs to be studied. A reasonable attitude towards the material basis of phenomena, and the impetus to decode it, should be maintained. At the same time, to understand the meaning of this "ideal" is to be free of materialism (Bekhtereva, 2007).

Ananev's considerations of the mechanisms which integrate psychic (mental) functions in understanding the structure of thought are of great interest here. According to his scheme, the development of mental properties takes the form of functional, operational, and motivational mechanisms (Ananev, 1971). Early development of functional mechanisms launches the phylogenetic program. They are formed long before the emergence of operational mechanisms. However, there is close interaction between functional and operational mechanisms. The development of operational mechanisms is required for a certain level of functional development. In turn, the development of operational mechanisms brings the functional mechanisms up to a new level, making them more advanced in their capabilities and functional systemization. In some periods of human ontogeny (e.g., school age, youth and maturity), symmetry and relative interaction between these two kinds of mechanisms are established. Ananev's conception attempts to consider the interrelationship between the biological and social aspects of mental activity. Here the functional mechanisms are viewed as determined by ontogenetic evolution as well as the biological organization, while the operational mechanisms are viewed as acquired in education, upbringing, and training. As for the motivational mechanisms, they refer to the personality level of human development.

Investigations of the functions of the psyche (Shadrikov \& Cheremoshkina, 1990; Shadrikov, 2007) show that general mental operations of analysis, synthesis, generalization, comparison, and abstraction are operational procedures. Thinking takes part in carrying out the psyche's functions of perception, memory, and other mental processes. In turn, these processes serve as the operational mechanisms of thinking. In thinking, certain mental functions are integrated, and appear in a form of mutual contribution. As such, the development of the psyche's function is simultaneously performed as the process of mental integration. 
Here it should be said that the mechanism of the psyche's functions in establishing the relationship between the object (thing) and its qualities (attributes) is the mechanism of thought generation. By addressing ourselves to the mechanism of integration of the object image and the thought about the object's qualities, we actually come to the issue of the mental representation of an image. This representation is made by thoughts associated with the qualities of the object. It occurs within behavior and activities, and is functional in nature. Thus, in the image one reveals one's thoughts (if any) about the qualities of the perceived object. These "thought-qualities" are important for one's actual forms of behavior, and for dealing with the aims that arise within such a behavior.

\section{Conclusion}

Our approach to understanding human thought and the process of its generation provides broad prospects for studying the evolution of human thought. By defining thought as a relationship between a thing and its qualities, we come to the conclusion that the thing's quality might be seen as a detector distinguishing the thing from other things (external objects). It is the qualities of things that establish the interrelationships between them. The qualities associated with the mental representation of the thing lead to the formation of its image and judgment about it (thing). Based on these thoughts, thinking manifests itself in judgment. As such, thinking is, on the one hand, a process of thought generation, and, on the other hand, a process that deals with thoughts.

It must be emphasized that the thought being generated by the subject contains not only the qualities of an external object, but also the qualities of its generator. Thus, any thought is personal in its nature. Personal consciousness is the unity and substantial integrity of thoughts generated by an individual. Individuals are not identical in their relationship to the same external object (thing). The coherence of conscious thoughts and their unity reflect the person's relationship to external objects and their completeness. This integration is employed to understand the outside world since a single generated thought is functional in nature. The mind enables an individual to be aware of the objective reality in which he finds himself. An ability to generate thoughts and establish relationships within a stream of consciousness is characteristic of human intelligence.

Finally, we would like to introduce some basic propositions drawn from the present study:

1. Human thought is functional, since it realizes the primary function of the psyche - that is, to maintain the operation of activity and behavior. The thought's functionality might be understood through some of the operations performed by an individual who thinks. They are: the selection of a thing from the surroundings or conditions in which the individual lives or operates; the determination of the thought's attributes; and the ascertainment of its functional significance. The things' images and their attributes are the products of the given operations carried out by such mental processes as sensation and perception. Thus, the unity of an image and its attributes (characteristics, properties) is taken to be a thought. 
2. A thought is referred to a thing as well as to a phenomenon and occurrence. It is an implicit substance of what is thought. This is a need-emotion-intentional substance existing in the human inner world. The individual's thought is linked to his behavior or motivation for activity, and is followed by emotional experience. Since it's related to need and experience, it differs from information, which is characterized particularly by meaning. The thought refers to the essentials of a thing, phenomenon, or occurrence.

3. The substantial thought is the relationship of a thing to its attributes (characteristics, properties) established by an individual who thinks. Here the individual is considered the subject of intellectual activity which involves thinking. The thought is generated by the individual. Thus, it is subjective in nature. The thought becomes subjective due to objectivation of the thinking subject's needs, the subject's moral principles, and the individual's perception of the sociocultural and situational factors.

4. Thinking is a process of thought generation. Generativity is a feature of thinking related to an individual's mentality or mind. Hence an individual's mentality is considered as his/her capacity to generate thoughts and work through thoughts. The mentality, thinking, and the capacity to generate thoughts are set out in unity, where the mind is the resulting characteristic of the thought generation process. In turn, the mind and intellect are functions of the individual's mentality, as well as the two levels of his mental activity. The mental content (images, ideas, judgment, notions) exists within these levels.

5. The mechanism of thought generation is a complex of mental processes through which the relationship between the thing and its attributes is established. The psychological analysis of this mechanism deals with an explanation of thinking that relies on a relationship determined by mental processes. Thinking takes place in perceiving and memorizing. When working through images, ideas, and notions, the individual makes judgments. The judgment is a primary representation of substantial thinking, or the process of thought generation.

6. A thought generated by an individual incorporates the physical properties of objective reality as well as his personal traits. Thus, it is personal in nature, and at the same time is a part of the individual's consciousness. Individuals differ in thoughts related to the same thing.

7. The mental activity of an individual refers to being aware of the meaning of single thoughts towards his acts, action, and deeds. By realizing his own behavior (activity), the individual acquires the idea of the subjective significance of own life.

\section{Acknowledgements}

The study was prepared within the framework of the Basic Research Program at the National Research University Higher School of Economics (HSE) in 2015. 


\section{References}

Abulkhanova, K. A. (1999). Psihologija i soznanie lichnosti (Problemy metodologii, teorii i issledovanija realnoj lichnosti): Izbrannye psihologicheskie trudy. [Psychology and personality awareness (Issues of methodology, theory and personality study): Selected psychological works]. Moscow: Moskovskij psihologo-socialnyj institut, Voronezh: MODJeK.

Abulkhanova-Slavskaja, K. A., \& Brushlinskjy, A. V. (1989). Filosofsko-psihologicheskaja koncepcija S. L. Rubinshtejna: K 100-letiju so dnja rozhdenija [Philosophical and psychological conception of S. L. Rubinstein: On the occasion of the centenary of the birth]. Moscow: Nauka.

Abulkhanova-Slavskaja, K. A. (1994). Socialnoe myshlenie lichnosti: problemy i strategii issledovanija [Personality social thinking: Problems and research strategies]. Psikhologicheskiy Zhurnal [Psychological journal], 4, 39-55.

Altmann, E. M., Trafton, J. G., \& Hambrick, D. Z. (2014). Momentary interruptions can derail the train of thought. Journal of Experimental Psychology: General, 143(1), 215-226. doi: 10.1037/a0030986

Ananev, B. G. (1977). O problemah sovremennogo chelovekovedenija [Issues of contemporary study of human nature]. Moscow: Nauka.

Aristotle (ca. 350 BCE). De anima (On the soul) (J. A. Smith, Trans.). Classical in the History of psychology. Toronto, Ontario: York University. Retrieved from http://psychclassics.yorku. ca/Aristotle/De-anima/index.htm (Originally published in Ross, W. D. (Ed.) (1930). The works of Aristotle. Vol. 3. Oxford: Clarendon Press).

Avugos, S., \& Bar-Eli, M. (2015). A second thought on the success-breeds-success model: Comment on Iso-Ahola and Dotson (2014). Review of General Psychology, 19(1), 106-111. doi: 10.1037/gpr0000024

Becker, B. W., Goodman, D. M., \& Macdonald, H. (2014). A thought on giving: toward an economic relational subjectivity. Journal of Theoretical and Philosophical Psychology, 34(4), 214228. doi: $10.1037 / \mathrm{a} 0037759$

Bekhtereva, N. P. (1978). The neurophysiological aspects of human mental activity, 2nd ed. Oxford : Oxford University Press.

Bekhtereva, N. P. (2007). Magija mozga i labirinty zhizni [The magic of brain and life labyrinths]. Moscow: ACT.

Bergson, H. (1935). The two sources of morality and religion. New York: Henry Holt and Company.

Bos, M. W., Dijksterhuis, A., \& van Baaren, R. (2012). Food for thought? Trust your unconscious when energy is low. Journal of Neuroscience, Psychology, and Economics, 5(2), 124-130. doi: $10.1037 / \mathrm{a} 0027388$

Bright, A. K., \& Feeney, A. (2014). The engine of thought is a hybrid: Roles of associative and structured knowledge in reasoning. Journal of Experimental Psychology: General, 143(6). doi: 10.1037/a0037653

Gallagher, K. E., Lisco, C. G., Parrott, D. J., \& Giancola, P. R. (2014). Effects of thought suppression on provoked men's alcohol-related physical aggression in the laboratory. Psychology of Violence, 4(1), 78-89. doi: http://dx.doi.org/10.1037/a0032304

Hart, R., Ivtzan, I., \& Hart, D. (2013). Mind the gap in mindfulness research: A comparative account of the leading schools of thought. Review of General Psychology, 17(4), 453-466. doi: $10.1037 / \mathrm{a} 0035212$

Huntsinger, J. R., Isbell, L. M., \& Clore, G. L. (2014). The affective control of thought: Malleable, not fixed. Psychological Review, 121(4), 600-618. doi: 10.1037/a0037669 
Ishiguro, H. (1990). Leibniz's philosophy of logic and language. 2nd ed. Cambridge: Cambridge University Press.

Locke, J. (1979). An essay concerning human understanding. P. H. Nidditch (Ed). Oxford: Clarendon Press.

Logan, G. D., Van Zandt, T., Verbruggen, F., \& Wagenmakers, E. (2014). On the ability to inhibit thought and action: General and special theories of an act of control. Psychological Review, 121(1), 66-95. doi: 10.1037/a0035230

Lohnberg, J. A., \& Altmaier, E. M. (2014). Thought intrusion among adults living with complex regional pain syndrome. Rehabilitation Psychology, 59(2), 171-175. doi: 10.1037/a0035945

Potebnja, A. A. (1926). Mysl i jazyk [Thought and language]. Complete works. Vol. 1. Kiev, Ukraine: State Ukraine Press.

Pribram, K. H. (1971). Languages of the brain: Experimental paradoxes and principles in neuropsychology. Englewood Cliffs, N.J.: Prentice-Hall.

Rubinstein, S. L. (1958). O myshlenii i putjah ego issledovanija [About the thinking and ways of its investigation]. Moscow: Izdatelstvo Akademii Nauk SSSR.

Rubinstein, S. L. (1973). Osnovy obshhej psihologii [Issues of general psychology]. Moscow: Pedagogica.

Rubinstein, S. L. (1997). Izbrannye filosofsko-psihologicheskie trudy. Osnovy ontologii, logiki i psihologii [Selected philosophical and psychological works. Fundamentals of ontology, logic and psychology]. Moscow: Nauka.

Shadrikov, V. D., \& Cheremoshkina, L. V. (1990). Mnemicheskie sposobnosti: razvitie i diagnostika [Mnemonic abilities: Development and diagnostics]. Moscow: Pedagogika.

Shadrikov, V. D. (2007). Mentalnoe razvitie cheloveka [Human mental development]. Moscow: Aspect-Press.

Shadrikov, V. D. (2013). Psihologija dejatelnosti cheloveka [Psychology of human activity]. Moscow: Institute of Psychology RAN.

Simonton, D. K. (2013). Creative thought as blind variation and selective retention: Why creativity is inversely related to sightedness. Journal of Theoretical and Philosophical Psychology, 33(4), 253-266. doi: http://dx.doi.org/10.1037/a0030705

Slavskaja, K A. (1968). Mysl v dejstvii (Psihologija myshlenija) [Thought in action (Thinking psychology)]. Moscow: Politizdat.

Smallwood, J. (2013). Searching for the elements of thought: reply to Franklin, Mrazek, Broadway, and Schooler (2013). Psychological Bulletin, 139(3), 542-547. doi: 10.1037/a0031019

Sudakov, K. V. (1993). Brain neuronal mechanisms of motivation and reinforcement: System organization of behavior. Journal of Integrative Physiology and Behavioral Science, 28(4), 396-407. doi: 10.1007/BF02690937

Thomas, L. E. (2013). Spatial working memory is necessary for actions to guide thought. Journal of Experimental Psychology: Learning, Memory, and Cognition, 39(6), 1974-1981. doi: $10.1037 / \mathrm{a} 0033089$

Vasiljuk, F. E., Zinchenko V. P., Meshcherjakov, B. G., Petrovskiy, V. A., Pruzhinin, B. I., \& Shchedrin, T. G. (2012). Metodologija psihologii: problemy i perspektivy [Methodology of psychology: Issues and prospects]. Moscow; St. Petersburg: Centr gumanitarnyh iniciativ.

von Humboldt, W. (1984). Izbrannye trudy po jazykoznaniju [Selected works in linguistics]. Moscow: Progress. 